\title{
GAMBARAN TINGKAT PENGETAHUAN IBU TENTANG MENYIKAT GIGI TERHADAP TERJADINYA KARIES PADA SISWA/I KELAS II SD AZIZI KECAMATAN MEDAN TEMBUNG
}

\author{
Susy Adrianelly Simaremare \\ Jurusan Keperawatan Gigi Poltekkes Kemenkes Medan
}

\begin{abstract}
Abstrak
Menyikat gigi bertujuan untuk memelihara kebersihan dan kesehatan mulut terutama gigi dan jaringan sekitarnya, untuk mencegah terjadinya karies gigi dan penyakit periodontal serta mencegah tertimbunya sisa - sisa makanan itu dapat menjadi media baik untuk pertumbuhan mikroorganisme sehingga dapat menyebabkan peradangan pada jaringan periodontium. Penelitian yang dilakukan adalah penelitian deskriptif dengan metode survey yang bertujuan untuk mengetahui gambaran tingkat pengetahuan ibu tentang menyikat gigi terhadap terjadinya karies pada anak kelas II SD Azizi Kecamatan Medan Tembung, Besar Sampel berjumlah 32 orang. Pengumpulan data menggunakan kuesioner yang diberikan secara langsung kepada ibu dan siswa/i. Hasil penelitian menunjukkan bahwa 40,62\% (13 orang) memiliki pengetahuan baik, 59,37\% (19 orang) memiliki pengetahuan sedang dan tidak ada (0\%) ibu yang memilki tingkat pengetahuan buruk mengenai tingkat pengetahuan ibu tentang menyikat gigi terhadap terjadinya karies.
\end{abstract}

Kata Kunci : Pengetahuan Ibu, Menyikat Gigi, Karies

\section{Pendahuluan}

Undang-undang Kesehatan No.93 Tahun 1992 menyatakan bahwa Hak dan Kewajiban setiap orang yang untuk memperoleh derajat kesehatan optimal serta wajib ikut serta dalam pemeliharaan dan meningkatkan derajat kesehatan perorangan,keluarga dan lingkungannya.

Perkembangan di dalam bidang kesehatan gigi sudah sedemikian maju, akan tetapi sangat disayangkan bahwa kemajuan ilmu kesehatan tersebut belum dapat dinikmati oleh seluruh lapisan masyarakat Indonesia.

Pada anak usia sekolah dasar dapat dilakukan penanaman dasar pola tingkah laku yang baik, yang dilakukan oleh orang tuanya dimana diharapkan orang tua dapat menanamkan disipilin mendidik dan mengarahkan tingkah laku anak supaya anak dapat bertingkah laku sesuai yang diharapkan. Dalam hal ini ibu dan anak merupakan kesatuan ikatan, dimana ibu merupakan anggota tim yang baik untuk melakukan pengawasan kesehatan dan untuk membantu menentukan kebiasaan di rumah. Tindakan penanaman disiplin dalam menjaga kesehatan gigi terhadap anak sekolah dasar merupakan tindakan untuk merubah pola tingkah laku sedini mungkin yang akan membawa manfaat untuk kemudian hari. Dalam usaha mencegah dan mengatasi masalah kesehatan gigi, maka pendekatan secara pendidikan merupakan salah satu hal yang terpenting dalam pemeliharaan kesehatan gigi dan mulut serta menanamkan perilaku sehat sejak dini.

Penyelengaraan kesehatan gigi dan mulut pada hakekatnya ditunjukkan kepada seluruh masyarakat yang bertujuan untuk meningkatkan derajat kesehatan dengan pendekatan pemeliharaan, peningkatan kesehatan (promotif), pencegahan penyakit (preventif), upaya pengobatan (kuratif), dan pemulihan kesehatan (rehabilitatif) yang diselenggarakan secara menyeluruh, terpadu dan berkesinambungan.

Peranan fungsi gigi sangat penting dalam kehidupan kita sehari-hari, yaitu sebagai sarana dalam proses pencernaan makanan tahap pertama. Bila gigi susunannya tidak teratur atau bila ada gigi yang hilang, maka proses pengunyahan kurang baik, akibatnya akan terjadi gangguan dalam proses pengunyahan sehingga terjadi gangguan dalam proses penyerapan makanan. Selain itu bentuk dan jumlah gigi mempengaruhi komunikasi atau fungsi berbicara. Pemeliharaan kesehatan gigi dapat dilakukan dengan membiasakan menyikat gigi minimal dua kali sehari yaitu pagi setelah sarapan dan malam sebelum tidur.

Berdasarkan SKRT (Survey Kesehatan Rumah Tangga) tahun 1995 dan SUSENAS (Survey Sosial Ekonomi Nasional) tahun 1998 dinyatakan bahwa masyarakat belum menyadari pentingnya memeliharaan kesehatan gigi dan mulut. Hal ini terlihat dari 22,5\% penduduk Indonesia tidak menyikat gigi dan dari $77,2 \%$ yang menyikat gigi hanya $8,1 \%$ yang menyikat gigi tepat waktu, oleh sebab itu perlu dilakukan suatu upaya untuk menjaga kebersihan gigi dan mulut dengan menyikat gigi secara teratur.

Kesehatan gigi sangat penting, karena akan berpengaruh terhadap kesehatan tubuh secara umum. Salah satu cara untuk menjaga kesehatan gigi adalah 
dengan meyikat gigi untuk mencegah timbulnya sisasisa makanan pada sela-sela dan permukaan gigi, yang apabila terus dibiarkan dapat menyebabkan terjadinya masalah pada gigi.

Masalah utama dalam rongga mulut anak adalah adanya karies gigi yang dihadapi oleh penduduk Indonesia dan Negara-negara berkembang laninnya. Karies merupakan suatu penyakit jaringan keras gigi, yaitu email, dentin dan sementum yang disebabkan oleh aktivitas jasad renik dalam suatu karbohidrat yang dapat diragikan. Tandanya adalah adanya demineralisasi jaringan keras gigi yang dikemudian diikuti oleh kerusakan bahan organik.

Penyebab terjadinya karies gigi adalah adanya interaksi dari berbagai faktor, diantaranya adalah faktor perilaku dalam memelihara kesehatan gigi dan mulut, faktor diet atau kebiasaan makan makanan yang mengandung gula atau sukrosa dan faktor ketahanan dan kekuatan gigi.

Menurut Riset Kesehatan Dasar (RISKESDAS) DEPKES RI tahun 2007, mengungkapkan kesehatan gigi dan mulut tetap menjadi masalah, dimana $72,1 \%$ penduduk negeri ini menderita karies, $46 \%$ diantaranya belum ditangani.

Berdasarkan hal tersebut di atas penulis ingin mengetahui gambaran tingkat pengetahuan ibu tentang cara menyikat gigi terhadap terjadinya karies pada anak kelas II SD Azizi Kecamatan Medan Tembung.

\section{Perumusan Masalah}

Berdasarkan latar belakang di atas, maka perumusan masalah adalah bagaimanakah gambaran tingkat pengetahuan ibu tentang cara menyikat gigi terhadap terjadinya karies pada anak kelas II SD Azizi Kecamatan Medan Tembung

\section{Tujuan}

\section{Tujuan Umum}

Penelitian ini dilakukan bertujuan untuk mengetahui gambaran tingkat pengetahuan ibu tentang cara menyikat gigi terhadap terjadinya karies pada anak kelas II SD Azizi Kecamatan Medan Tembung.

\section{Tujuan Khusus}

1. Untuk mengetahui tingkat pengetahuan ibu tentang waktu menyikat gigi pada siswa/i kelas II SD Azizi Kecamatan Medan Tembung.

2. Untuk mengetahui tingkat pengetahuan ibu tentang tujuan menyikat gigi pada siswa/i kelas II SD Azizi Kecamatan Medan Tembung.

3. Untuk mengetahui tingkat pengetahuan ibu tentang cara menyikat gigi pada siswa/i kelas II SD Azizi Kecamatan Medan Tembung.

4. Untuk mengetahui tingkat pengetahuan ibu tentang jenis sikat gigi yang baik pada siswa/i kelas II SD Azizi Kecamatan Medan Tembung.

5. Untuk mengetahui tingkat pengetahuan ibu tentang penggunaan pasta gigi pada siswa/i kelas II SD Azizi Kecamatan Medan Tembung.

\section{Manfaat Penelitian}

1. Menambah wawasan dan ilmu pengetahuan ibu tentang cara penyikat gigi pada anak siswa/i kelas II SD Azizi Kecamatan Medan Tembung

2. Sebagai masukan bagi peneliti lain dan sebagai bahan referensi diperpustakaan Jurusan Kesehatan Gigi Politeknik Kemenkes Medan

3. Untuk menambah wawasan pengetahuan dan pengalaman bagi peneliti untuk menerapkan ilmu yang telah diperoleh.

\section{Kerangka Konsep}

Variabel Independen

Variabel Dependen

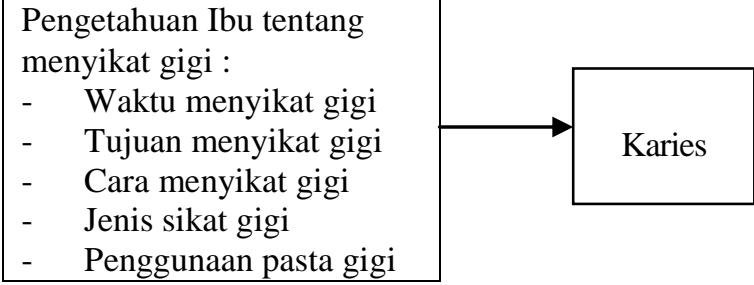

\section{Definisi Operasional}

1. Pengetahuan adalah segala sesuatu yang diketahui ibu tentang menyikat gigi yang diketahui dari jawaban ibu tentang tindakan menyikat gigi seharihari melalui kuesioner.

2. Ibu adalah seorang wanita yang mempunyai anak SD kelas II.

3. Terjadinya karies gigi adalah hal-hal yang dapat menyebabkan terjadinya gigi yang berlubang.

4. Menyikat gigi adalah suatu cara yang dilakukan untuk membersihkan gigi dengan menggunakan sikat gigi dan pasta gigi dengan memperhatikan waktu, tujuan, cara menyikat gigi, jenis sikat gigi, penggunaan pasta gigi.

\section{Jenis Penelitian}

Jenis penelitian yang dilakukan adalah penelitian deskriptif dengan metode survey, yang bertujuan untuk mengetahui gambaran tingkat pengetahuan ibu tentang menyikat gigi terhadap terjadinya karies pada anak kelas II SD Azizi Kecamatan Medan Tembung.

\section{Lokasi Penelitian}

Lokasi penelitian yang dilakukan adalah SD Azizi Kecamatan Medan Tembung.

\section{Populasi Penelitian}

Populasi adalah keseluruhan objek penelitian atau objek yang akan diteliti (Notoatmodjo, S, 2005). Populasi dalam penelitian ini adalah ibu dari siswa/i SD Azizi Kecamatan Medan Tembung sebanyak 32 orang.

\section{Sampel}

Sampel adalah sebagian yang diambil dari keseluruhan objek yang diteliti dan dianggap mewakili seluruh populasi. Dalam pengambilan sampel pada penelitian ini mengarah pada pendapat Suharsini Arikunto, 
yang menyatakan apabila subjek penelitian lebih dari 100 orang, maka lebih baik diambil semua, jika subjek kurang dari 100 orang, dapat diambil $10-15 \%$ atau $20-25 \%$ atau lebih.

Jadi karena sampel penelitian kurang dari 100, maka jumlah sampel yang diambil oleh peneliti adalah seluruh ibu dari siswa/i kelas II SD Azizi Kecamatan Medan Tembung, yaitu sebanyak 32 orang.

\section{Jenis dan Cara Pengumpulan Data}

Pengumpulan data dilakukan dengan menggunakan metode survey yaitu pengambilan data secara langsung pada siswa-siswi dengan menggunakan kuesioner untuk mengetahui gambaran tingkat pengetahuan ibu tentang menyikat gigi terhadap terjadinya karies pada siswa/i kelas II SD Azizi Kecamatan Medan Tembung.

Penelitian dilakukan oleh peneliti sendiri dengan cara melakukan pengumpulan data dengan memberikan kuesioner kepada siswa/i untuk mengisi lembar kuesioner setelah itu kuesioner dikumpul kembali.

Teknik pengukuran menggunakan alat dan bahan sebagai berikut :

Alat terdiri dari :

1. Sikat gigi

2. Kuesioner

3. Phantom

\section{Pengolahan Data}

Pengolahan data dilakukan melalui proses pengolahan data yaitu :

\section{Editing}

Yaitu memeriksa kuesioner yang telah diisi dengan tujuan data memberikan hasil yang menggambarkan masalah yang diteliti, kemudian data dikelompokkan dengan menggunakan aspek pengukuran.

2. Coding

Yaitu dengan merubah jawaban-jawaban responden ke dalam bentuk angka-angka sehingga memudahkan dalam pengolahan data.

3. Tabulating

Yaitu memasukan data penelitian ke dalam tabel untuk mempermudah analisa data dan pengolahan data serta pengambilan kesimpulan (Arikunto, 2006).

Pengolahan data yang dilakukan dalam penelitian ini yaitu dengan membagikan kuesioner yang berisi 10 pertanyaan kepada jumlah sampel penelitian, mengumpulkan kuesioner yang telah selesai dikerjakan, kemudian diperiksa, setelah itu pengkodean atau pemberian angka - angka terhadap kuesioner untuk setiap :

1. Jawaban yang benar di beri angka atau nilai satu (1)

2. Jawaban yang salah diberi angka atau nilai nol (0) Untuk memperoleh tinggi, sedang, dan rendahnya tingkat pengetahuan digunakan :

RUMUS = Skor Maksimum - Skor Minimum

$$
\begin{aligned}
& =\frac{10-0}{3} \\
& =3,33
\end{aligned}
$$

Masa kriteria pengetahuan yang diperoleh dengan penggenapan adalah:

Tinggi $=7-10$

Sedang $=4-6$

Rendah $=1-3$

\section{Analisa Data}

Analisa data dilakukan dengan cara manual untuk memberikan informasi mengenai gambaran tingkat pengetahuan ibu tentang menyikat gigi terhadap terjadinya karies pada siswa/i kelas II SD Azizi Kecamatan Medan Tembung.

Kemudian data yang telah dikumpulkan dianalisis secara deskriptif dan disajikan dalam tabel distribusi frekuensi.

\section{Hasil}

Berdasarkan hasil penelitian yang dilakukan pada 32 orang ibu siswa/i kelas II SD Azizi Kecamatan Medan Tembung maka diperoleh hasil sebagai berikut :

Tabel 1.Karakteristik Responden Berdasarkan Umur

\begin{tabular}{|c|c|c|c|}
\hline No & Umur & $\begin{array}{c}\text { Jumlah } \\
(\mathbf{n})\end{array}$ & $\begin{array}{c}\text { Persentase } \\
(\boldsymbol{\%})\end{array}$ \\
\hline 1 & $25-30$ & 16 & 50 \\
\hline 2 & $31-36$ & 7 & 21,87 \\
\hline 3 & $37-42$ & 9 & 28,12 \\
\hline
\end{tabular}

Dari tabel 1 diperoleh bahwa tingkat pengetahuan ibu terhadap terjadinya karies berdasarkan umur 25-30 sebanyak 16 orang (50\%), umur 31-36 sebanyak 7 orang $(21,87 \%)$, umur $37-42$ sebanyak 9 orang $(28,12 \%)$.

Tabel 2.Distribusi Frekuensi Tingkat Pengetahuan Ibu tentang Menyikat Gigi terhadap Terjadinya Karies pada Siswa/i Kelas II SD Azizi Kecamatan Medan Tembung

\begin{tabular}{|c|l|c|c|}
\hline \multirow{2}{*}{ No } & \multirow{2}{*}{ Kriteria } & \multicolumn{2}{|c|}{ Jumlah } \\
\cline { 3 - 4 } & & $\begin{array}{c}\text { Jumlah } \\
(\mathbf{n})\end{array}$ & $\begin{array}{c}\text { Persentase } \\
(\boldsymbol{\%})\end{array}$ \\
\hline 1 & Baik & 13 & 40,62 \\
2 & Sedang & 19 & 59,37 \\
3 & Buruk & 0 & 0 \\
\hline \multicolumn{2}{|c|}{ Total } & 32 & 100 \\
\hline
\end{tabular}

Dari tabel 2 diperoleh bahwa tingkat pengetahuan tentang terjadinya karies dengan kriteria baik sebanyak 13 orang $(40,62 \%)$, persentase tingkat pengetahuan ibu dengan kriteria sedang sebanyak 19 orang $(59,37 \%)$ dan persentase tingkat pengetahuan ibu dengan kriteria buruk tidak ada $(0 \%)$. 


\section{Pembahasan}

Berdasarkan Tabel 1 diperoleh bahwa karakteristik responden berdasarkan umur dapat diketahui bahwa gambaran tingkat pengetahuan ibu tentang menyikat gigi terhadap terjadinya karies pada siswa kelas II SD Azizi Kecamatan Medan Tembung berdasarkan umur 25-30 dari 16 responden dengan kriteria baik 8 orang dan sedang 8 orang (25\%), umur 31-36 dari 7 responden dengan kriteria baik hanya 3 orang $(9,37 \%)$ dan kriteria sedang 4 orang $(12,5 \%)$ dan umur 37-42 dari 9 responden dengan kriteria baik hanya 3 orang $(9,37 \%)$ dan kriteria sedang $(18,75 \%)$.

Berdasarkan tabel 2 distribusi frekuensi tingkat pengetahuan ibu tentang terjadinya karies gigi pada siswa/i kelas II SD Azizi Kecamatan Medan Tembung dapat dilihat bahwa persentase tingkat pengetahuan ibu pada umumnya adalah sedang diketahui dari 32 responden tentang waktu menyikat gigi hanya 18 orang $(28,12 \%)$ yang sudah mengetahui waktu menyikat gigi yang efektif. Hal ini diartikan bahwa masih ada ibu yang tidak mengetahui waktu yang tepat dan cara yang tepat untuk menyikat gigi. Menurut Monang Panjaitan (1997) mengatakan bahwa penyikatan gigi harus dilakukan minimal dua kali sehari yaitu pagi sesudah sarapan dan malam sebelum tidur, karena menurut hasil penelitian bila plak disingkirkan setiap hari secara sempurna maka tidak akan menimbulkan efek pada rongga mulut.

Tingkat pengetahuan ibu tentang tujuan menyikat gigi dari 32 responden,10 orang $(31,25 \%)$ memiliki tingkat pengetahuan sedang. Hal ini diartikan bahwa masih banyak ibu yang tidak mengetahui tentang tujuan menyikat gigi yang tepat. Menurut Monang Panjaitan (1997), menyikat gigi bertujuan untuk memelihara kebersihan dan kesehatan mulut terutama gigi serta jaringan sekitarnya, menimbulkan rasa segar dalam mulut, mencegah timbulnya sisa makanan pada sela gigi dan permukaan gigi, dan mencegah terjadinya karies gigi serta penyakit periodontal.

Tingkat pengetahuan ibu tentang cara menyikat gigi dari 32 responden, hanya sebagian ibu 12 orang $(37,5 \%)$ memiliki tingkat pengetahuan sedang. Hal ini diartikan bahwa masih ada ibu yang tidak mengetahui cara menyikat gigi yang baik dan benar. Menurut Departemen Kesehatan Republik Indonesia (1995) bahwa teknik penyikatan gigi harus dapat membersihkan semua permukaan gigi dan gusi secara efisien terutama daerah interdental, pergerakan dari sikat gigi tidak boleh menyebabkan kerusakan jaringan gusi dan teknik penyikatan harus sederhana, tepat dan efisien dalam waktu.

Sebagian besar ibu 18 orang $(56,25 \%)$ sudah mengetahui jenis sikat gigi yang baik. Namun masih ada 14 orang ibu $(43,75 \%)$ yang belum mengetahui jenis sikat gigi yang baik dan tepat untuk menyikat gigi. Menurut Ardyan Gilang Ramadhan (2010), bahwa jenis sikat gigi yang baik adalah sikat yang fit atau sesuai dengan mulut, terasa nyaman saat digunakan dan harus dapat menjangkau semua gigi yang ada dalam mulut termasuk gigi paling belakang. Jenis sikat dan bulu sikat yang saling silang lebih efektif membersihkan plak dengan menggunakan berbagai teknik penyikatan, terutama plak yang terdapat di selasela gigi.

Sebagian besar ibu 13 orang $(40,6 \%)$ sudah mengetahui penggunaan pasta gigi. Hal ini diartikan bahwa sebagian ibu belum mengetahui tentang penggunaan pasta gigi. Hal ini sesuai dengan pendapat Ardyan Gilang Ramadhan (2010), bahwa kita harus lebih sering menggunakan pasta gigi yang mengandung fluoride yang berfungsi untuk mencegah, menghentikan dan memperbaiki kerusakan gigi dalam batas-batas tertentu.

\section{Simpulan}

Hasil penelitian dapat disimpulkan bahwa gambaran tingkat pengetahuan ibu tentang menyikat gigi terhadap terjadinya karies pada siswa/i kelas II SD Azizi Kecamatan Medan Tembung adalah sebagai berikut:

1. Tingkat pengetahuan ibu tentang menyikat gigi terhadap terjadinya karies berdasarkan umur 25-30 dari 16 responden, 8 orang $(25 \%)$ dengan kriteria baik, umur 31-36 dari 7 responden, 3 orang $(9,37 \%)$ dengan kriteria baik dan 4 orang $(12,5 \%)$ dengan kriteria sedang, umur $37-42$ dari 9 responden , 3 orang $(9,37 \%)$ dengan kriteria baik dan 6 orang $(18,75 \%)$ dengan kriteria sedang.

2. Tingkat pengetahuan tentang waktu menyikat gigi dari 32 responden, 23 orang $(71,87 \%)$ memiliki tingkat pengetahuan baik dan 9 orang $(28,12 \%)$ memiliki tingkat pengetahuan sedang.

3. Tingkat pengetahuan tentang tujuan menyikat gigi dari 32 responden, 22 orang $(68,75 \%)$ memiliki tingkat pengetahuan baik dan 10 orang $(18,55 \%)$ memiliki tingkat pengetahuan sedang.

4. Tingkat pengetahuan tentang cara menyikat gigi dari 32 responden, 20 orang $(62,5 \%)$ memiliki tingkat pengetahuan baik dan 12 orang $(37,5 \%)$ memiliki tingkat pengetahuan sedang.

5. Tingkat pengetahuan tentang jenis sikat gigi dari 32 responden, 18 orang $(56,25 \%)$ memiliki tingkat pengetahuan baik dan 14 orang $(43,75 \%)$ memiliki tingkat pengetahuan sedang.

6. Tingkat pengetahuan tentang penggunaan pasta gigi dari 32 responden, 19 orang $(59,37 \%)$ memiliki tingkat pengetahuan baik dan 13 orang $(40,6 \%)$ memiliki tingkat pengetahuan sedang

\section{Saran}

1. Diharapkan kepada ibu siswa/i lebih memperhatikan kesehatan gigi dan mulut keluarga, serta dapat mempraktekkan dalam kehidupan sehari - hari

2. Diharapkan kepada kepala sekolah SD Azizi Kecamatan Medan Tembung agar dapat bekerja sama dengan Puskemas setempat untuk melakukan penyuluhan tentang kesehatan gigi dan mulut khususnya tentang menyikat gigi. 
3. Disarankan kepada orangtua agar membawa anaknya ke Pelayanan Kesehatan Gigi minimal setiap 6 bulan sekali.

\section{Daftar Pustaka}

Besford, Jhon, 1996, Mengenal Gigi Anda, ARCAN, Jakarta.

Boedihardjo, Msc, 1985, Pemeliharaan Kesehatan Gigi Keluarga, Airlangga University Press, Surabaya.

Budiharto. 2008, Metodologi Penelitian Kesehatan Dengan Contoh Bidang Ilmu Kesehatan Gigi, EGC, Jakarta.

Edwina, Sally, 1991, Dasar-Dasar Karies Penyakit dan Penanggulangannya. EGC, Jakarta.

Gilang, Ardyan, R, 2010, Serba-Serbi Kesehatan Gigi dan Mulut, Bukune, Jakarta Selatan.
Panjaitan, Monang. 1997. Etiologi Karies Gigi dan Penyakit Periodontal, USU Press, Medan

Notoatmodjo, Soekidjo, 2003, Ilmu Kesehatan Masyarakat, Rineka Cipta, Jakarta.

Notoatmodjo, Soekidjo, 2005, Metodologi Penelitian Kesehatan, Rineka Cipta, Jakarta

Pratiwi Dona, 2007, Gigi Sehat, Buku Kompas, Jakarta.

Tarigan, 1990, Karies Gigi., Hipokrates, Jakarta. Depkes , RI, 2000 